GASPARI, Elio. 2003. A ditadura derrotada. O sacerdote e o feiticeiro. São Paulo : Companhia das Letras.

\title{
HISTORIOGRAFIA, MEMÓRIA E HISTÓRIA DO REGIME MILITAR BRASILEIRO
}

\author{
Marcos Napolitano
}

O livro A ditadura derrotada, grande sensação do mercado editorial brasileiro, é composto por quatro partes: 1) "O sacerdote e o feiticeiro" (respectivamente os generais Ernesto Geisel e Golbery do Couto e Silva), que expõe a trajetória biográfica dos dois personagens; 2) "O caminho de volta", relatando a ascensão de Geisel ao poder, incluindo a transição com o governo Médici, a montagem da equipe e o combate à oposição armada; 3) "No planalto", sobre a política de governo e 4) "A derrota", que analisa o impacto da surpreendente derrota eleitoral que o partido do governo (Aliança Renovadora Nacional-ARENA) sofreu em 1974. O livro faz parte da coleção sobre o regime militar escrita por Gaspari, cuja proposta é contar a história do "consulado militar", expressão que ele utiliza para nomear o regime militar brasileiro, projeto completado pelos outros três livros já publicados ( $A$ ditadura envergonhada, $A$ ditadura escancarada e $A$ ditadura encurralada). Nesse grande projeto editorial, Gaspari usa seu talento narrativo para recompor os detalhes da vida palaciana durante o regime militar, enfatizando aspectos da luta política interpessoal que opôs os principais personagens militares que dividiram o poder nos 20 anos que durou o regime. No volume $A$ ditadura derrotada temos a síntese das virtudes e problemas de ordem historiográfica que estão presentes nos outros volumes.

Gaspari, já no "Prefácio", lista a quantitativamente impressionante relação de fontes primárias e assume: "Este livro não existiria sem a colaboração dos dois generais" (GASPARI, 2003, p. 16). Golbery deu a Gaspari 25 caixas de arquivo, com cerca de cinco mil documentos. Geisel recebeu-o em vinte entrevistas a partir de 1984, até 1996. Além disso, Heitor Ferreira, secretário pessoal de Geisel, cedeu-lhe o arquivo privado, seu diário (1964-1976) e 120 fitas cassetes com gravações de outubro de 1973 a março de 1974, totalizando 220 horas de conversações entre Geisel e colaboradores. Essa impressionante base documental, no entanto, revela uma questão heurística importante: a inevitável pré-seleção do material documental, na medida em que foi cedido pelos próprios protagonistas da história contada no livro. É praticamente um ponto de consenso entre historiadores que a organização, guarda e transmissão das fontes historiográficas deve ser parte da própria reflexão que delimita as possíveis abordagens de um tema.

O livro em questão concentra-se na imagem daqueles que a memória social vem considerando os principais estrategistas da ditadura, Ernesto Geisel e Golbery do Couto e Silva.

A apresentação dos perfis pessoais dos dois personagens, estratégia fundamental na narrativa historiográfica de Gaspari, aponta para homens autoritários, mas coerentes. A imagem traçada do General Geisel é ambígua, retratado como um homem duro, porém coerente, que enfrentou a "indisciplina" a "anarquia militar" com mão de ferro. Nas palavras do autor: "Geisel recebeu uma ditadura triunfalista, feroz contra os adversários e benevolente com os amigos. Decidiu administrá-la de maneira que ela se acabasse. Não fez isso porque desejava substituí-la por uma democracia. Assim como não acreditava na existência de uma divindade na direção dos destinos do universo, não dava valor ao sufrágio universal como forma de escolha dos governantes. Queria mudar porque tinha a convicção de que faltavam ao regime brasileiro estrutura e força para perpetuar-se" (idem, p. 15).

Mesmo sua politização precoce é matizada pelo caráter castrense: "Se é possível dizer que houve dois tenentismos, um profissional e outro político, alistara-se no primeiro" (idem, p. 37). A questão que podemos levantar é que, justamente, fica muito difícil estabelecer um "tenentismo profissional", expressão que não se vê na historiografia clássica sobre o tema, constituindo-se em pura - e eficaz - figura de retórica do autor.

Na seqüência, Gaspari faz uma breve e linear exposição da carreira de Geisel: ingresso no Colégio Militar em 1925; Tenente em 1929; participante da Revolução de 1930, como parte do IV ${ }^{\circ}$ Grupo de Artilharia a Cavalo (Rio 
Grande do Sul), e da Revolução de 1932, como parte das forças legalistas; retorno ao Rio de Janeiro, para a Escola de Artilharia; Major em 1945, com estágio na Escola de Comando do Fort Leavenworth (EUA). E arremata: "As inquietações cotidianas do Major Geisel relacionavam-se muito mais com a qualidade do Exército em que vivia do que com os grandes problemas nacionais" (idem, p. 44)

A possível contradição entre o Geisel rebelde e o soldado disciplinado e profissional é resolvida na medida em que Gaspari reforça a explicação que o personagem biografado dá de si mesmo. Conforme seu próprio depoimento, Geisel aceitava como legítimas as manifestações de força feitas dentro da hierarquia militar (com as que teriam ocorrido em 1930, 1937 e 1945). Todas essas revoltas militares haviam sido feito "dentro da hierarquia", segundo o General, determinadas pelo quartel-general e apoiadas pelo Comandante da unidade. Portanto, o militar Geisel legitima (e oculta) seu lado político, seus interesses e sua participação no jogo de poder dentro do Exército, elementos que, em princípio, alimentariam a "anarquia militar", expressão constantemente utilizada por Gaspari. Por exemplo, em 1955, o Tenente-Coronel Geisel, ao ser nomeado pelo Marechal Lott para a Petrobrás, tornando-se parte da equipe administrativa do complexo industrial petrolífero em formação, teria dado uma demonstração de coerência, coragem e desprendimento, repreendendo o Marechal, dizendo-lhe: "O senhor não podia se insurgir contra um presidente da República que o tinha nomeado" (idem, p. 54). Geisel referia-se ao chamado "golpe preventivo" que destituiu Carlos Luz da Presidência da República, garantindo a posse de Juscelino Kubitschek.

Em 1957, durante seu comando em Quitaúna (São Paulo), a morte do filho, atropelado pelo trem, "alterou a noção que Geisel tinha da própria existência" (idem, p. 55). A partir daí, conforme Gaspari, o sisudo militar tornava-se um homem amargurado, dedicado à vida pública unicamente pelo senso de dever. No Conselho Nacional do Petróleo, Geisel mostrava-se mais uma vez coerente: "Um Coronel anticomunista da $2^{\mathrm{a}}$ Seção do EME [Estado-Maior do Exército] incomodava muita gente, mas um oficial capaz de hostilizar Capuava [uma refinaria privada concorrente da Petrobrás] sentado no CNP [Conselho Nacional do Petróleo] incomodava muito mais" (idem, p. 66). Temos a impressão de ler sobre a vida de um Robespierre virtuoso, embora à direita.

Apesar de reiterar boa parte da visão dos depoentes, o próprio Gaspari dá-nos um exemplo de como os depoimentos memorialísticos, que formam boa parte das suas fontes, podem mentir, quando da sua exposição sobre a tentativa de golpe contra a posse de Goulart: "A derrota do golpismo foi tamanha que, com o tempo, ninguém se dispôs a segurar o caixão da crise de 1961" (idem, p. 82). Seguem-se depoimentos de golpistas confessos que passaram a se dizer "favoráveis à posse de Jango", como Odílio Denys, Cordeiro de Farias e Carlos Lacerda. Entretanto, essa técnica de crítica aos depoimentos dos envolvidos não é utilizada ao longo do livro, talvez como tributo à importância que os biografados tiveram na própria construção do livro, imprimindolhe, em certo sentido, a delimitação heurística.

Finalmente, como o golpe de 1964, o "antipolítico" e "militar profissional" General Geisel voltava ao círculo do poder como Chefe do Gabinete Militar de Castello Branco. Já de volta ao Rio, em 1962, "era um perfeito conspirador de 1964" comandando um "canil" (idem, p. 88), participando do núcleo conspirador que contava com a participação de Cordeiro de Faria e Antônio Muricy. O objetivo desse núcleo: atrair Castello Branco, o Chefe do Estado-Maior do Exército para a conspiração, só conseguida em janeiro de 1964. Sintomaticamente, o próprio Gaspari sugere o processo nada fortuito de seletividade das fontes históricas preservadas pelos envolvidos: "dos planos do golpe sobraram poucos documentos e vagas reminiscências" (idem, p. 88). Depois da sua passagem pela Casa Militar e contrariado pela posse de Costa e Silva, Geisel foi nomeado para a presidência da Petrobrás, em 1969. Sua vida e trajetória como empresário da estatal pouco aparecem no livro, que enfatiza a pureza do militar duro, profissional e incorruptível.

Sobre Golbery do Couto e Silva, Elio Gaspari apresenta-nos um perfil menos monumentalizado e mais humano, embora sempre frisando a sua coerência, ainda que do "lado errado" (em tempo: o autor condena o autoritarismo e a violência do regime militar). Filho de família aristocrática arruinada, Golbery freqüentou a Escola Militar do Realengo, sendo um aluno quase tão bom quanto Prestes e Geisel (os melhores). Em 1939, como Capitão, tornou-se membro de apoio do Conselho de Segurança Nacional (CSN). Participou da Força Expedicionária Brasileira (FEB), mas "não ouviu nenhum tiro" na II ${ }^{a}$ Guerra Mundial (idem, p. 118). Com a criação da Escola Superior de Guerra (ESG), consolidava-se na sua visão de mundo a "premissa de que o subdesenvolvimento brasileiro era produto da falta de competência e articulação de sua elite". Assim, Golbery via na ESG a possibilidade de "sistematizar o debate dos problemas do País" (idem, p. 123). Iniciou, então, sua carreira de intelectual castrense, com o ciclo de conferências "Aspectos geopolíticos do Brasil", em 1952. 
Conforme Elio Gaspari, o feiticeiro Golbery foi o redator do "Memorial dos coronéis" (fevereiro de 1954) e do "Manifesto dos generais" (agosto de 1954), documentos que precipitaram a crise política que culminou no suicídio de Getúlio Vargas. Em outubro de 1954, novas conferências: "Planejamento e a Segurança Nacional". Nelas desenvolveu os conceitos de "guerra subversiva" e "guerra total". Defendeu a idéia de uma Política de Segurança Nacional planejada que decidiria o momento e a forma por que o governo declararia guerra a parte do seu povo (idem, p. 135). Iniciava-se a codificação da Doutrina de Segurança Nacional, por volta de 1953, uma mescla das idéias do Estado Novo com as novas "apostilas americanas", sintetizadas por Cordeiro de Farias em 1952. Em 1956, o Coronel Golbery foi para o Estado-Maior do Exército e conheceu Geisel e Figueiredo, uma das trindades mais importantes do regime militar. Em fevereiro de 1961, assumiu a Secretaria-Geral do CSN e o controle do Serviço Federal de Informação e Contra-Informação, base do futuro Serviço Nacional de Informações (SNI). Em 1962, promovido a General, Golbery saiu do Exército e ajuda a criar o IPÊS (Instituto de Pesquisa e Estudos Sociais) (fundado por Augusto Trajano Antunes, dono da ICOMI, e Antônio Galloti, Presidente da Light and Power). Ao lado do IBAD (Instituto Brasileiro de Ação Democrática) (criado por Ivan Hasslocher para financiar os candidatos conservadores das eleições de 1962), funcionaria como instituição golpista, cuja base social estava fincada entre os empresários.

As fontes primárias são transformadas em "monumento", conforme a expressão de Jacques Le Goff, sendo pouco problematizadas pelo autor. Um exemplo disso pode ser visto quando Gaspari descreve o último manifesto de Golbery contra Goulart, redigido em $1^{\circ}$ de abril de 1964, intitulado "Missão a cumprir pelo governo", demarcando seis pontos: "três óbvios (ordem, anti-corrupção e inflação), um desejo ('elevar o nível de educação política do povo'), um sonho (garantir eleições limpas e posse para eleitos). Um outro ponto versava sobre as Forças Armadas: reintegrar no princípio constitucional, restabelecendo profissionalismo, hierarquia e autoridade, para depois cuidar do reaparelhamento" (idem, p. 165). O juízo de valor feito por Gaspari parte do princípio da transparência da fonte e da sinceridade das suas idéias, nunca problematizadas como ideologia (o que necessariamente não quer dizer mentira ou cinismo instrumental diante da "realidade").

Em um certo sentido, reiterando a memória liberal sobre o golpe e o regime militar, Elio Gaspari sintetiza o primeiro governo do regime (Castello Branco) nos seguintes termos: "O projeto de reforma castelista mal arranhou o estilo de vida do patronato brasileiro. Faltava-lhe a base política para buscar nas urnas um mandato que lhe permitisse uma aproximação com o centro, da mesma forma que lhe faltava disposição para tentar criar uma base militar que lhe permitisse, ao menos, dispensar o amparo que recebia do patronato. Era a anarquia que dava o tom ao regime, obrigando-o a simular uma corrosiva aparência de unidade militar" (idem, p. 171; sem grifo no original). Essa parece ser uma avaliação feita pelos próprios protagonistas biografados e chancelada pelo autor.

A sucessão de Emílio Médici, figura de que pouco se fala no livro, surge como um movimento personalista e exclusivamente militar, como nas velhas crônicas palacianas. A escolha recaiu sobre Geisel, tecnocrata e militar, com um pé no castelismo e na "nova ordem" posterior ao Ato Institucional n. 5 (AI-5) (idem, p. 188). Golbery e Cordeiro de Farias coordenaram o lobby para fazer de Geisel o candidato a Presidente. Orlando Geisel (Ministro do Exército) e Figueiredo (Chefe do Gabinete Militar) conseguiram fazer a ponte com Médici, que não gostava de Golbery. Conforme o livro, Geisel aceitou por puro profissionalismo e patriotismo. Ponto. No capítulo do "Grande eleitor", Gaspari reforça um certo "individualismo metodológico" que perpassa o livro, para pensar a dinâmica da História. Geisel surge como "soldado disciplinado", esperando a decisão do "eleitor" Médici (idem, p. 224). O jogo de bastidores e articulações maiores entre os grupos políticos e econômicos desaparece completamente. A dinâmica política do regime militar sempre é explicada a partir de idiossincrasias militares, ocorridas na caserna ou no palácio.

O capítulo mais chocante, intitulado "Esse troço de matar", reconstitui a conversa de Geisel com o General Dale Coutinho (em 16 de fevereiro de 1974). Mesmo em se tratando de tortura, mantém-se um perfil de Geisel "duro, mas honesto e coerente", defendendo a morte dos subversivos dentro de uma lógica estritamente militar. Geisel não se via como político e Gaspari, em certo sentido, homologa essa auto-imagem. Em certos trechos, surge nitidamente uma fala monumentalizada, direcionada muito mais aos pósteros e não ao seu interlocutor direto. Por exemplo: "Não vou dar aos políticos o que eles querem, mas vou viver com eles [...] porque, senão, como é? Nós vamos, nós temos a outra alternativa, que é ir para uma ditadura [...]que é uma solução muito pior" (idem, p. 320). Outro exemplo de fala para ser ouvida pela posteridade: "Eu não tenho razões personalistas. Não me queixo do Médici [...] Ele [Costa e Silva] fez o AI-5 constrangido como o Castello fez o AI-2 constrangido, também. Porque, por tendência, eles não fariam, eles foram quase obrigados. Agora, eu 
não quero ser obrigado, quando for o caso, eu aplico [...] eu vou aplicar é racionalmente, com moderação e com decência e pronto" (idem, p. 323).

Geisel e Golbery não aparecem em nenhum momento como constrangidos pela história. São os heróis do livro e, por tabela, da história contada por Gaspari que, habilmente, consegue manter-se em um estilo crítico e irônico diante dos personagens. Mas o núcleo da narrativa e da análise aí incluída, a coerência e um certo idealismo patriótico e conservador - nada disso é tocado. Nada melhor que as palavras do autor - de hábil fatura, diga-se - que dão início à trilogia para reforçar nossa análise: "Entre 1974, ao assumir o governo, e 1979, ao deixá-lo, [Geisel] transformou uma Presidência inerte, entregue a um colegiado de superministros, num governo imperial. Converteu uma ditadura amorfa, sujeita a períodos de anarquia militar, num regime de poder pessoal,e quando consolidou esse poder - ao longo de um processo que culmina em 12/10/77 - desmantelou o regime. Quanto assumiu havia uma ditadura sem ditador. No fim de seu governo, havia um ditador sem ditadura" (GASPARI, 2002, p. 35).

Em suma, as trajetórias biográficas apresentadas ao longo do livro, articulada à análise dos fatos do período, revela um olhar que condena o autoritarismo, mas mantém-se preso a uma teia narrativa factual e valorativa que, em última instância, é norteada pela visão de mundo dos dois biografados, figuras centrais na construção do regime militar, embora tenham conseguido passar à história como os seus demolidores. As obras de Gaspari parecem situar-se dentro de uma tradição de análise, muito forte em alguns setores da imprensa, que vêm reiterando uma memória liberal sobre o regime militar. Arriscaríamos dizer que os traços principais dessa corrente seriam os seguintes: a) o golpe foi um acontecimento fortuito, sem projeto ou conspiração eficazes, produzido pela incompetência política de João Goulart; b) os conspiradores civis, inocentes úteis, foram progressivamente alijados do novo regime ou romperam com ele, ao perceberem o endurecimento político progressivo; c) havia um núcleo liberal no Exército que foi neutralizado pela "linha dura", entre 1967 e 1974 e obrigado por ela a aceitar medidas de violência política e d) a pressão dos quartéis estaria na base do endurecimento do regime, portanto, este processo não seria fruto de uma estratégia política. Nessa tradição de análise, a responsabilidade dos civis e militares "liberais" que foram artífices do golpe e do regime fica atenuada, pois eles teriam perdido o controle do processo político, abrindo espaço para a violência política da “ditadura escancarada" de 1968 a 1974.

Outras questões centrais para uma análise mais acurada do regime simplesmente desaparecem da agenda: a tradição de liberalismo doutrinário e autoritarismo instrumental, marca das elites brasileiras; o amplo controle do processo político e da violência autorizada, por parte da hierarquia militar brasileira, apesar das tensões e lutas políticas inerentes ao exercício do poder (o que poderia colocar em xeque a tese da "anarquia militar" que não parece tão determinante no caso brasileiro); a vacilação dos liberais tendo que optar entre a crítica à censura e a necessidade de uso da força contra a guerrilha e a opção por um autoritarismo institucional por parte dos castelistas, complementado pela violência política instrumental e localizada (que poderia ir além da tradicional dicotomia entre "linha dura" e "moderados").

Tendo o mérito de recolocar, de maneira apaixonada e com estilo, o tema do golpe e do regime militar no debate público, o(s) livro(s) de Gaspari, no entanto, corre(m) o risco de ensejar uma leitura acrítica e cheia de armadilhas metodológicas. Ocupando, de maneira legítima, o vácuo deixado pela historiografia política que abriu mão de "contar a história" em prol de uma hiper-teorização nem sempre acessível ao leitor culto, mas leigo, As ilusões armadas demandam uma leitura crítica que faça saltar, da bela articulação narrativa, os problemas teórico-metodológicos e as escolhas ideológicas do autor, cuja força sedutora da narrativa consegue ocultar.

Marcos Napolitano (napoli@ufpr.br) é Doutor em História Social pela Universidade de São Paulo (USP) e Professor do Departamento de História da Universidade Federal do Paraná.

\section{REFERÊNCIAS BIBLIOGRÁFICAS}

GASPARI, E. 2002. A ditadura envergonhada. As ilusões armadas. São Paulo : Cia. das Letras. .2003. A ditadura derrotada. O sacerdote e o feiticeiro. São Paulo : Cia. das Letras. 